\title{
Efektivitas Pelatihan Peningkatan Kompetensi Guru Bidang Kelautan Perikanan Teknologi Informasi dan Komunikasi di Indonesia
}

\section{The Effectiveness of the Teacher Competency Improvement Training in the Field of Marine, Fisheries, Information and Communication Technology in Indonesia}

\author{
Al Azhar \\ Balai Pengembangan Penjaminan Mutu Pendidikan Vokasi Bidang Kelautan Perikanan \\ Teknologi Informasi dan Komunikasi, Jalan Diklat No. 30, Pattallassang, Gowa \\ alazhar@kemdikbud.go.id
}

Naskah diterima tanggal 19 Mei 2021. Naskah direvisi tanggal 14 Juni 2021.

Naskah disetujui tanggal 16 Juni 2021

\begin{abstract}
Abstrak
Guru harus mengoptimalkan kompetensi dan kinerjanya dalam menjalankan tugas sebagai pendidik sehingga proses pembelajaran dapat berjalan efektif dan efisien. Oleh karena itu, perlu upaya untuk meningkatkan kinerja guru melalui program pendidikan dan pelatihan yang diselenggarakan oleh lembaga diklat pemerintah. Penelitian ini bertujuan untuk mengidentifikasi tingkat efektivitas pelaksanaan peningkatan kompetensi guru bidang kelautan, perikanan, teknologi infomasi, dan komunikasi (KPTK) di Indonesia sebagai program dari Kementerian Pendidikan dan Kebudayaan melalui LPPPTK KPTK sebagai unit pelaksana teknis. Data yang digunakan dalam penelitian ini adalah sasaran dan realisasi peserta pelatihan guru bidang KPTK tahun 2015-2019. Metode pencarian data dan informasi lainnya dengan penelusuran pustaka/literatur dan menelaah data sekunder. Analisis data studi ini adalah analisis deskriptif kualitatif. Hasil penelitian menunjukkan bahwa peningkatan kompetensi guru bidang KPTK yang dilaksanakan selama lima tahun (20152019) sudah efektif. Hal ini terbukti dengan terlaksananya seluruh program diklat sesuai dengan jadwal waktu yang ditentukan, rapinya penyelenggaraan seluruh kegiatan diklat, efisiensi dalam penggunaan sarana dan prasarana yang tersedia, dan tercapainya sasaran yang telah ditetapkan bagi program diklat dari total sasaran 15.096 orang, terealisasi sebanyak 20.901 orang $(138,5 \%)$.
\end{abstract}

Kata kunci: Efektivitas, Peningkatan Kompetensi, Guru KPTK

Abstract
Teachers have to optimize their competence and performance in carrying out their duties as
educators so that the learning process might run effectively and efficiently. Therefore, efforts
are needed to improve teacher performance through education and training programs 
organized by government education and training institutions. This study aimed to identify the level of effectiveness in implementing teacher competency improvement in the fields of marine, fisheries, information technology and communication in Indonesia as a program of the Ministry of Education and Culture through LPPPTK KPTK as a technical implementation unit. The data used in this study were the targets and realization of teacher training participants in the marine, fisheries, information technology and communication field in 2015-2019. Methods of searching for data and other information by searching literature / literature and analyzing secondary data. The data analysis of this study was a qualitative descriptive analysis. The results showed that the improvement of teacher competency in the KPTK field which was carried out for five years (2015-2019) was effective. It was proven by the implementation of all education and training programs in accordance with the specified time schedule, the orderly implementation of all education and training activities, efficiency in the use of available facilities and infrastructure, and the achievement of the targets set for the education and training program out of a total target of 15,096 people, which was realized as many as 20,901 people (138.5\%).

Keywords: Effectiveness, Competency Improvement, Teachers

\section{PENDAHULUAN}

Berdasarkan Undang-undang Nomor 20 Tahun 2003 tentang sistem pendidikan nasional, menyatakan bahwa pendidikan adalah usaha sadar dan terencana untuk mewujudkan suasana belajar dan proses pembelajaran agar peserta didik secara aktif mengembangkan potensi dirinya untuk memiliki kekuatan spiritual keagamaan, pengendalian diri, kepribadian, kecerdasan, akhlak mulia, serta keterampilan yang diperlukan dirinya, masyarakat, bangsa, dan negara.

Peningkatan mutu pendidikan di Indonesia harus ditekankan pada peningkatan kompetensi dan softskill peserta didik mulai jenjang pendidikan dasar hingga perguruan tinggi (Dewi et al., 2014; Sumaryati, 2013). Untuk mewujudkan tujuan ini sekaligus menggali potensi peserta didik yang ada, maka diperlukan orang-orang ahli pada bidangnya, sesuai keahlian yang dimiliki, termasuk para pendidik (Fitria et al., 2019). Pendidik di sini salah satunya adalah guru. Guru haruslah orang yang dengan sepenuh hati mau untuk mendidik sehingga dapat membentuk calon penerus bangsa yang nantinya diharapkan mampu memajukan Indonesia (Susilowati et al., 2013). Selain itu, guru sebagai komponen pelaksana proses pembelajaran dituntut harus mempunyai kemampuan/kompetensi yang sesuai dengan tujuan pembelajaran (Hapsari dan Widiasari, 2018). Dalam menjalankan tugas sebagai pendidik, guru harus mengoptimalkan kompetensi dan kinerjanya sehingga proses pembelajaran dapat berjalan efektif dan efisien (Somantri et al., 2019).

Kinerja guru dapat dinyatakan sebagai tingkat keberhasilan seorang guru secara keseluruhan dalam periode waktu tertentu yang dapat diukur berdasarkan tiga indikator, 
yaitu: penguasaan bahan ajar, kemampuan mengelola pembelajaran, dan komitmen menjalankan tugas (Karimah, 2016). Selain itu, kinerja guru juga dipengaruhi oleh kepribadian, sikap, dan motivasi guru. Oleh karena itu, perlu upaya untuk meningkatkan kinerja guru selain dari guru itu sendiri. Salah satu upaya pemerintah untuk meningkatkan kinerja guru yaitu dengan mengadakan suatu program pendidikan dan pelatihan yang disebut diklat (Karimah, 2016).

Diklat adalah salah satu cara dalam mengukur kompetensi aparatur pemerintah. Adapun istilah diklat adalah proses penyelenggaraan belajar mengajar dalam rangka meningkatkan kemampuan Pegawai Negeri Sipil (Karimah, 2016). Diklat adalah proses penyelenggaraan belajar mengajar guna meningkatkan kompetensi bagi calon pegawai negeri sipil (CPNS) dan pegawai negeri sipil. Peningkatan kompetensi yang dikemas dalam bentuk diklat adalah bagian proses pendidikan formal, termasuk untuk guru sebagai sasaran (Nugroho, 2017). Diklat biasanya berkaitan dengan kemampuan atau keterampilan seseorang untuk dikembangkan. Diklat meliputi dua fungsi sekaligus yaitu fungsi pendidikan dan fungsi pelatihan yang merupakan satu kesatuan yang tidak dapat dipisahkan (Karimah, 2016).

Beberapa bentuk diklat, baik yang langsung diselenggarakan oleh pemerintah maupun melalui lembaga-lembaga diklat (Rusdin, 2017). Salah satu lembaga diklat yang menyelenggarakan pelatihan bagi para guru yaitu Lembaga Pengembangan dan Pemberdayaan Pendidik dan Tenaga Kependidikan Bidang Kelautan Perikanan Teknologi Informasi dan Komunikasi (LPPPTK KPTK). LPPPTK KPTK merupakan Unit Pelaksana Teknis (UPT) pusat dibawah Direktorat Jenderal Guru dan Tenaga Kependidikan (Ditjen GTK) Kementerian Pendidikan dan Kebudayaan. Salah satu tugas LPPPTK KPTK yang tertuang dalam Permendikbud Nomor 18 Tahun 2015 tentang Organisasi dan Tata Kerja adalah melaksanakan berbagai pelatihan peningkatan kompetensi guru bidang KPTK. Pelatihan diberikan agar guru mampu mengembangkan dan meningkatkan kompetensi yang dimiliki serta mengimbaskan kompetensi kepada guru lain dan mengimplementasikannya di lingkungan sekolahnya. Dalam upaya peningkatan mutu pendidikan, guru menjadi komponen utama yang sangat menentukan karena kualitas pendidikan salah satunya sangat bergantung pada kompetensi guru sebagai pelaku pendidikan (Wardinur \& Mutawally, $\underline{2019)}$. 
Namun demikian, tujuan yang diharapkan belum tentu sesuai dengan realitas yang ada. Berdasarkan laporan penyelenggaraan kegiatan dan pengamatan sejak tahun 2015 hingga 2019, pada beberapa pelatihan bidang KPTK masih ditemukan jumlah peserta yang hadir mengikuti pelatihan sampai tuntas lebih sedikit dibanding dengan jumlah sasaran yang ditetapkan. Kondisi demikian tentunya akan berdampak pada tidak tercapainya peningkatan kompetensi guru bidang KPTK, yang pada akhirnya perubahan guru dalam kinerjanya (pengetahuan, sikap, dan keterampilan) tidak dapat terwujud. Kajian efektivitas pelaksanaan pelatihan bidang KPTK belum ada dilaksanakan. Olehnya studi ini fokus pada penggalian informasi dan pengolahan data untuk mengetahui tingkat efektivitas pelaksanaan pelatihan bidang KPTK yang diselenggarakan LPPPTK KPTK dari tahun 2015 sampai 2019.

\section{METODE PENELITIAN}

Data yang digunakan dalam penelitian ini adalah hasil pengumpulan data peserta pelatihan-pelatihan bidang KPTK yang diselenggarakan LPPPTK KPTK dari tahun 2015 sampai 2019. Data tersebut berupa total sasaran yang direncanakan untuk diberi peningkatan kompetensi bidang KPTK setiap tahunnya, kemudian dibandingkan dengan jumlah peserta yang hadir mengikuti pelatihan dan dinyatakan lulus. Metode pencarian data dan informasi lainnya dengan penelusuran pustaka/literatur dan menelaah data sekunder. Data sekunder adalah data yang diperoleh secara tidak langsung, berupa keterangan yang ada hubungannya dengan penelitian. Kajian literatur memerlukan tahapan antara lain menyusun daftar bacaan, membaca, dan menganalisis literatur (Putra et al., 2020). Literatur yang digunakan dalam kajian ini adalah literature primer (e.g. hasil penelitian, jurnal ilmiah), dan literatur sekunder (e.g. buku, artikel daring). Teknik analisis yang digunakan adalah analisis deskriptif kualitatif (Kurniati et al., 2019). Pada penelitian ini menganalisis (1) sasaran peserta pelatihan KPTK dari tahun 2015 sampai 2019, (2) realisasi peserta yang mengikuti pelatihan KPTK sampai tuntas dan dinyatakan lulus. Pelaksanaan pelatihan dapat dikatakan efektif jika jumlah realisasi pelatihan minimal sama dengan total sasaran yang direncanakan atau dengan kata lain keberhasilan dalam mencapai tujuan/sararan yang telah ditetapkan (Julifan, $\underline{2015)}$.

\section{HASIL DAN PEMBAHASAN}

Pelatihan peningkatan kompetensi guru bidang kelautan, perikanan, teknologi informasi dan komunikasi sejalan dengan indikator kinerja LPPPTK KPTK. Setiap tahun 
LPPPTK KPTK menentukan jumlah sasaran guru yang diberikan pelatihan. Untuk mengukur efektivitas pelaksanaan peningkatan kompetensi guru, sasaran tersebut dibandingkan dengan jumlah peserta yang hadir mengikuti pelatihan dan dinyatakan lulus.

\section{Pelaksanaan Tahun 2015}

Guru kelautan, perikanan, teknologi informasi dan komunikasi yang ditingkatkan kompetensinya pada tahun 2015, meliputi (1) pendidikan dan pelatihan guru keahlian bidang perikanan; (2) pendidikan dan pelatihan guru keahlian bidang kelautan; (3) pendidikan dan pelatihan guru keahlian bidang teknologi informasi dan komunikasi.

Pendidikan dan pelatihan guru keahlian bidang perikanan dilaksanakan di Pusat Pengembangan dan Perberdayaan Pendidik dan Tenaga Kependidikan (PPPPTK) Pertanian Cianjur pada bulan September 2015 dan di Balai Pendidikan dan Pelatihan (BPPP) Banyuwangi pada Bulan Desember 2015. Sementara itu, pendidikan dan pelatihan guru keahlian bidang teknologi informasi dan komunikasi dilaksanakan di LPMP Sulawesi Selatan pada bulan November 2015 dan di PPPPTK Bidang Otomotif dan Elektronika (BOE) Malang pada bulan Desember 2015. Realisasi capaian pendidikan dan pelatihan guru keahlian bidang kelautan, perikanan, teknologi informasi dan komunikasi (KPTK) disajikan pada Tabel 1.

Tabel 1.

Sasaran dan Realisasi Capaian Pendidikan dan Pelatihan Guru Keahlian Bidang KPTK

\begin{tabular}{|l|l|l|l|l|}
\hline No & Kegiatan & $\begin{array}{l}\text { Sasaran } \\
(\text { Orang })\end{array}$ & $\begin{array}{l}\text { Realisasi } \\
(\text { Orang })\end{array}$ & $\begin{array}{l}\text { Persentase } \\
\text { ketercapaian } \\
(\%)\end{array}$ \\
\hline 1. & Pelatihan guru bidang kelautan & 20 & 21 & 105,0 \\
\hline 2. & Pelatihan guru bidang perikanan & 120 & 111 & 92,5 \\
\hline 3. & $\begin{array}{l}\text { Pelatihan guru bidang keahlian teknologi } \\
\text { informasi dan komunikasi }\end{array}$ & 120 & 120 & 100,0 \\
\hline & Total & $\mathbf{2 6 0}$ & $\mathbf{2 5 2}$ & $\mathbf{9 6 , 9}$ \\
\hline
\end{tabular}

Berdasarkan pada Tabel 1, realisasi fisik pendidikan dan pelatihan guru bidang keahlian teknologi informasi dan komunikasi mencapai 100\%, dimana terdapat sasaran 120 
orang guru dan 120 guru juga yang dilatih. Sementara itu, realisasi fisik bidang kelautan mencapai 105\% (sasaran 20 orang guru kelautan yang dilatih, realisasinya 21 orang). Capaian bidang perikanan sebesar 92,50\% (sasaran 120 guru perikanan, realisasi 111 guru). Hal ini disebabkan ketidakhadiran peserta ketika diundang pelatihan.

Pelatihan peningkatan kompetensi berkelanjutan $(\mathrm{PKB})$ yang diperuntukan terhadap guru mata pelajaran TIK/KKPI jenjang SMP/SMA/SMK seluruh Indonesia dalam menerapkan kurikulum 2013. Sasaran guru yang dilatih sebanyak 1.250 orang, dengan realisasi sebanyak 1.384 pendidik atau sebesar $110,72 \%$.

\section{Pelaksanaan Tahun 2016}

Guru produktif dan adaptif yang ditingkatkan kompetensinya sesuai bidang kelautan, perikanan, teknologi informasi dan komunikasi pada tahun 2016 memiliki sasaran 3.072 orang dengan realisasi 3.046 orang (lihat Tabel 2), meliputi pelatihan instruktur nasional (IN) program guru pembelajar dan pengembangan keprofesian berkelanjutan (PKB). Pelatihan IN guru pembelajaran terdiri pelatihan IN program guru pembelajar bidang teknologi informasi dan komunikasi (TIK) SMA/SMK dan PKB guru mapel SMA dan SMK. Sementara itu PKB terdiri atas 7 kegiatan, yaitu Assessment Calon Assessor LSP, Ujicoba Perangkat Assesment, Penyusunan Dokumen Free Assesment, Pelaksanaan Assesment, Pembekalan Peserta dan Pendampingan, Pengelolaan LSP Program Keahlian Ganda Guru SMK, dan Workshop Pengembangan Model Ujian Soal Berstandar Nasional (USBN).

Tabel 2.

Sasaran dan Realisasi Capaian Peningkatan Kompetensi Guru Bidang Kelautan Perikanan Teknologi Informasi dan Komunikasi Tahun 2016

\begin{tabular}{|l|l|c|c|c|}
\hline No & Komponen Kegiatan & $\begin{array}{c}\text { Sasaran } \\
\text { (Orang }\end{array}$ & $\begin{array}{c}\text { Realisasi } \\
\text { (Orang) }\end{array}$ & $\begin{array}{c}\text { Persentase } \\
\text { Ketercapaian } \\
(\%)\end{array}$ \\
\hline 1 & $\begin{array}{l}\text { Pelatihan IN Program Guru } \\
\text { Pembelajar Bidang TIK SMA/SMK }\end{array}$ & 320 & 317 & 99,1 \\
\hline 2 & PKB Guru Mapel SMA dan SMK & 110 & 107 & 97,3 \\
\hline 3 & Assessment Calon Assessor LSP & 25 & 23 & 92,0 \\
\hline 4 & Ujicoba Perangkat Assesment & 15 & 15 & 100,0 \\
\hline 5 & $\begin{array}{l}\text { Penyusunan Dokumen Free } \\
\text { Assesmen }\end{array}$ & 15 & 15 & 100,0 \\
\hline 6 & Pelaksanaan Assesment & 25 & 24 & 96,0 \\
\hline 7 & $\begin{array}{l}\text { Pembekalan Peserta dan } \\
\text { Pendampingan Keahlian Ganda }\end{array}$ & 2.470 & 2.453 & 99,3 \\
\hline
\end{tabular}




\begin{tabular}{|l|l|l|l|l|}
8 & $\begin{array}{l}\text { Pengelolaan LSP Program Keahlian } \\
\text { Ganda Guru SMK }\end{array}$ & 2 & 2 & 100,0 \\
\hline 9 & Pengembangan Model USBN & 90 & 90 & 100,0 \\
\hline & Total & $\mathbf{3 . 0 7 2}$ & $\mathbf{3 . 0 4 6}$ & $\mathbf{9 9 , 2}$ \\
\hline
\end{tabular}

Kegiatan pelatihan IN program guru pembelajar bidang TIK SMA/SMK terdapat sasaran 320 orang dan terealisasi sebanyak 317 orang. Jika dihitung, persentase ketercapaian komponen ini yaitu sebesar $99.06 \%$. Pencapaian nilai ini tergolong besar, karena tingkat kehadiran peserta dalam setiap kegiatan pelatihan sangat tinggi. Pelatihan IN tersebut dilaksanakan sebanyak 2 (dua) angkatan.

1. Angkatan pertama dilaksanakan di LPMP Sulawesi Selatan (Mata Pelajaran TIK SMA/SMK), BP PAUDNI Makassar (Mapel Teknik Komputer Jaringan dan Rekayasa Perangkat Lunak), PPPPTK BMTI Bandung (Mata Pelajaran TIK SMA/SMK), PPPPTK TK PLB Bandung (Mapel Rekayasa Perangkat Lunak dan Multimedia), dan PPPPTK PKn IPS Malang (Mata Pelajaran TIK SMA/SMK, Teknik Komputer Jaringan dan Rekayasa Perangkat Lunak).

2. Angkatan Kedua dilaksanakan di PPPPTK TK PLB Bandung (Mapel Teknik Komputer Jaringan dan Multimedia), dan PPPPTK PKn IPS Malang (Mata Pelajaran Multimedia)

Sementara itu, pendidikan dan Pelatihan PKB guru Mapel SMA/SMK dalam suboutput ini merupakan Diklat Vokasi Mapel Kelautan dan Perikanan. Kegiatan ini dilaksanakan di Hotel Same Makassar, khususnya bagi guru-guru bidang keahlian budidaya rumput laut, sedangkan di BPPP Banyuwangi diperuntukan bagi guru bidang keahlian Nautika Kapal Penangkap Ikan (NKPI), Teknika Kapal Penangkap Ikan (TKPI), dan Nautika Kapal Niaga (NKN). Sasaran untuk diklat vokasi ini sebanyak 110 orang, namun peserta yang hadir sebanyak 107 orang, terdiri atas 47 di BPPP Banyuwangi dan 60 orang di Hotel Same Makassar. Realisasi capaian diklat ini sebesar 97,27\%.

Berdasarkan Tabel 2, dapat dilihat bahwa kegiatan calon assessor LSP, jumlah peserta yang diundang sebanyak 25 orang, namun yang hadir sebanyak 23 orang atau persentase sebesar 92. Assesement calon asesor LSP dilaksanakan di Politeknik Pertanian (Politani) Negeri Pangkep. Peserta diantaranya Dosen dan Mahasiswa Politani Negeri 
Pangkep; Dosen Universitas Negeri Makassar (UNM); dan staf LPPPTK KPTK Gowa. Sedangkan Narasumber berasal dari BNSP. Pelaksanaan kegiatan selama 2 hari (26 s.d 27 November 2016). Ujicoba Perangkat Assesment diselenggarakan pada 2 (dua) tempat yaitu Fakultas Teknik UNM dan Politani Negeri Pangkep. Peserta pada kegiatan ujicoba perangkap assessment sama dengan peserta assessment calon assessor, tetapi pada kegiatan ini ada penambahan peserta dari guru SMKN 1 Palangga, SMKN 2 Barru, SMK Muhammadiyah Bontoala, dan SMKN 4 Takalar. Pelaksanaannya selama 2 (dua) hari yaitu tanggal 2 s.d 3 Desember. Penyusunan Dokumen Free Assessment dilaksanakan pada tanggal 5 s.d 6 Desember 2016.

\section{Pelaksanaan Tahun 2017}

Pelaksanaan peningkatan kompetensi guru bidang KPTK pada tahun 2017 terdiri atas pelatihan Instruktur Nasional (IN) in service program keahlian ganda, pelatihan in service program keahlian ganda, pelatihan Basic Training Safety (BST), dan Training of Trainer (ToT) 6.10. Total sasaran keahlian ganda sebanyak 1.546 orang, terdiri atas IN 157 orang dan In service 1.389 orang. Sedangkan BST sebanyak 120 orang, dan ToT 6.10 sebanyak 30 orang. BST adalah pelatihan yang diperuntukan untuk guru-guru kelautan yang bertujuan agar guru/peserta pelatihan memiliki bekal pengetahuan tentang sebab kecelakan di laut yang tidak seharusnya terjadi, sehingga kecelakaan dapat dihindari dan semua kecelakan dapat ditiadakan, hingga tercapai bebas kecelakaan. Salah satu cara mencegah kecelakaan kerja yaitu dengan menerapkan kaidah-kaidah keselamatan dan kesehatan di tempat kerja, yang harus dipatuhi semua karyawan. Pelaksanaan Diklat BST, LPPPTK KTPK bekerjasama dengan Sekolah Tinggi Perikanan (STP) Jakarta. Jumlah peserta sasaran diklat BST sebanyak 120 orang, yang dibagi menjadi 2 gelombang yaitu bulan November dan Desember 2017. Pelaksanaan kegiatan dilangsungkan di STP Jakarta. Total peserta yang hadir sebanyak 87 orang. Sementara itu, diklat ToT 609 merupakan model pelatihan yang dikhususkan untuk para pengajar/instruktur yang akan melatih atau mengajar calon-calon pelaut. Diklat ToT ini adalah program diklat selama 80 jam atau setara dengan 10 hari kerja. Pelaksanaan Diklat ini diselenggarakan di Balai Pendidikan dan Pelatihan Transportasi Laut (BP2TL) Jakarta, pada tanggal 22 s.d 29 November 2017. Jumlah peserta yang mengikuti kegiatan ini sebanyak 30 orang. 
Tabel 3.

Sasaran dan Realisasi Capaian Peningkatan Kompetensi Guru Bidang Kelautan Perikanan Teknologi Informasi dan Komunikasi Tahun 2017

\begin{tabular}{|c|l|c|c|c|}
\hline No & \multicolumn{1}{|c|}{ Komponen Kegiatan } & $\begin{array}{c}\text { Sasaran } \\
(\text { Orang }\end{array}$ & $\begin{array}{c}\text { Realisasi } \\
(\text { Orang) }\end{array}$ & $\begin{array}{c}\text { Persentase } \\
\text { Ketercapaian } \\
(\boldsymbol{\%})\end{array}$ \\
\hline 1 & Pelatihan IN Keahlian Ganda & 157 & 157 & 100,0 \\
\hline 2 & Pelatihan in service Keahlian Ganda & 1.389 & 1.088 & 78,3 \\
\hline 3 & Basic training safety (BST) & 120 & 87 & 72,5 \\
\hline 4 & Training of trainer (ToT) 6.10 & 30 & 30 & 100,0 \\
\hline & Total & $\mathbf{1 . 6 9 6}$ & $\mathbf{1 . 3 6 2}$ & $\mathbf{8 0 , 3}$ \\
\hline
\end{tabular}

Pelatihan IN Keahlian Ganda bidang KPTK dijabarkan menjadi 2 (dua) tahap. Gelombang pertama dilaksanakan di LPMP Provinsi Sulawesi Selatan, pada tanggal 3 s.d 12 Maret 2017. Jumlah peserta sebanyak 37 orang. Tahap kedua diselenggarakan di Same Hotel Makassar pada tanggal 23 s.d 29 Agustus 2017. Jumlah peserta 120 orang. Total peserta IN yang telah didiklat tahun 2017 sebanyak 157 orang, sesuai dengan jumlah sasaran. Total realisasi fisik sub-output ini sebesar $100 \%$.

Pelatihan IN Keahlian Ganda ini dimaksudkan untuk menjaring guru-guru yang berkompeten dan lulus menjadi mentor program guru pembelajar bidang KPTK. Terdapat 10 paket keahlian yang menjadi prioritas yaitu Multimedia, Rekayasa Perangkat Lunak, Teknik Komputer Jaringan, Teknika Kapal Penangkap Ikan, Nautika Kapal Penangkap Ikan, Nautika Kapal Niaga, Nautika Kapal Penangkap Ikan, Agribisnis Perikanan Air Laut dan Payau, dan Teknologi Hasil Pengelolaan Perikanan. Penyiapan calon instruktur yang akan menjadi fasilitator di dalam proses In-1 dan In-2, bersifat substantif, yaitu sesuai dengan paket-paket keahlian yang dipilih untuk Program Keahlian Ganda bagi guru produktif.

Kegiatan pembekalan IN Keahlian Ganda dilaksanakan sebelum dimulainya kegiatan In-1, adapun tugas IN adalah sebagai berikut:

1. Mempersiapkan dan mempelajari perangkat modul Program Keahlian Ganda.

2. Membelajarkan, melatih, membimbing, dan mengevaluasi Program Keahlian Ganda sesuai paket keahliannya.

3. Membimbing peserta dalam melaksanakan praktik kerja di bengkel sesuai dengan paket keahliannya. 
4. Mengevaluasi keterlaksanaan pembelajaran dan hasil belajar peserta Program Keahlian Ganda.

5. Membuat laporan pelaksanaan dan hasil evaluasi dan ketercapaian belajar peserta Program Keahlian Ganda.

Diklat in service Program Keahlian Ganda dilaksanakan dengan formula On 1 - In 1 - On 2 - In 2. Kegiatan ini dimulai bulan Desember 2016 (On 1) sampai dengan Oktober 2017. Tempat kegiatan dilangsungkan di LPPPTK KPTK dan beberapa sekolah (diutamakan SMK) yang memenuhi syarat menjadi Pusat Belajar (PB) yang telah ditunjuk oleh LPPPTK KPTK. Pelaksanaan On 1 di sekolah asal/sekolah magang peserta diklat, bulan Desember 2016 hingga Februari 2017. Kegiatan In 1 dilaksanakan pada tanggal 25 Maret s.d 24 Mei 2017. Jumlah peserta yang diundang sebanyak 1.389 peserta dari beberapa mata pelajaran, sedangkan yang hadir sebanyak 1.088 orang. Secara rinci, sasaran dan realisasi pelatihan in service Keahlian Ganda dapat dilihat pada Tabel 4.

\section{Tabel 4.}

Sasaran dan Realisasi Pelatihan In Service Keahlian Ganda

\begin{tabular}{|c|l|c|c|c|}
\hline No & \multicolumn{1}{|c|}{ Kompetensi Keahlian } & $\begin{array}{c}\text { Sasaran } \\
\text { (Orang }\end{array}$ & $\begin{array}{c}\text { Realisasi } \\
\text { (Orang) }\end{array}$ & $\begin{array}{c}\text { Persentase } \\
\text { Ketercapaian } \\
(\boldsymbol{\%})\end{array}$ \\
\hline 1 & Teknik Komputer dan Jaringan (TKJ) & 501 & 384 & 76,6 \\
\hline 2 & Multimedia & 378 & 310 & 82,0 \\
\hline 3 & Rekayasa Perangkat Lunak (RPL) & 135 & 100 & 74,1 \\
\hline 4 & Nautika Kapal Penangkap Ikan (NKPI) & 174 & 133 & 76,4 \\
\hline 5 & Teknika Kapal Penangkap Ikan (TKPI) & 44 & 36 & 81,8 \\
\hline 6 & Nautika Kapal Niaga (NKN) & 43 & 35 & 81,4 \\
\hline 7 & Teknika Kapal Niaga (TKN) & 10 & 9 & 90,0 \\
\hline 8 & $\begin{array}{l}\text { Agribisnis Perikanan Air Payau dan } \\
\text { Laut }\end{array}$ & 74 & 58 & 78,4 \\
\hline 9 & Teknologi Pengolahan Hasil Perikanan & 30 & 23 & 76,7 \\
\hline & Total & $\mathbf{1 . 3 8 9}$ & $\mathbf{1 . 0 8 8}$ & $\mathbf{7 8 , 3}$ \\
\hline
\end{tabular}

Berdasarkan pada tabel 4, terlihat bahwa ketidakhadiran peserta di setiap mapel pada tahap In-1 keahlian ganda, sangat bervariasi. Alasan ketidakhadiran peserta juga bervariasi, salah satunya waktu pelaksanaan diklat cukup lama. Total peserta diklat yang tidak hadir sebanyak 301 guru. Dengan demikian dari 1.389 peserta, total yang hadir sebanyak 1.088 orang. Peserta-peserta yang hadir tersebut, setelah mengikuti diklat dan diseleksi dengan 
berbagai indikator penilaian, tidak semua dinyatakan lulus. Jumlah peserta yang tidak lulus sebanyak 20 orang, sehingga total peserta yang lulus sebanyak 1.068 orang.

\section{Pelaksanaan Tahun 2018}

Peningkatan kompetensi guru bidang KPTK tahun 2018 diprioritaskan untuk pengembangan keprofesian berkelanjutan (PKB) dan program revitalisasi SMK. Jumlah sasaran pada kegiatan ini sebanyak 350 orang, terealisasi 418 orang. Persentase ketercapaian sasaran PKB dan revitalisasi SMK pada tahun 2018 sebesar 119,4\%. Selain itu, program keahlian ganda dengan target 48 orang, dapat ditingkatkan kompetensinya sebanyak 78 guru (ketercapaian 159,18\%).

1. PKB Bidang KPTK dimaksudkan melatih calon instruktur sesuai kriteria yang mampu meningkatkan kemampuan guru yang akan dilatihnya dalam melaksanakan tugasnya melalui peningkatan kompetensi baik pedagogi maupun profesional, serta memiliki performa sebagai pendidik dan pemimpin bagi peserta didiknya. Kegiatan ini dilaksanakan pada bulan November 2018 di tiga region yaitu Medan, Jakarta, dan Makassar. Diklat ini difokuskan pada mata pelajaran TIK dan KKPI jenjang SMA/SMK. Suasana PKB bidang KPTK region Medan dapat dilihat pada Gambar $1 \mathrm{a}$.

2. Peningkatan kompetensi guru program revitalisasi SMK

Revitalisasi SMK dilakukan dengan bentuk peningkatan kompetensi guru bidang keahlian kemaritiman dan TIK. Terdapat 10 SMK yang dijadikan sebagai pusat belajar (PB) antara lain SMK Perguruan Cikini Jakarta, SMKN 36 Jakarta, SMKN 1 Jepara, SMK Wikrama Bogor, SMKS Pelayaran Muhammdiyah Tuban, SMKN 3 Tegal, SMKN 10 Semarang, SMKN 2 Subang, dan SMKN 1 Mundu Cirebon. Kegiatan tersebut diawali dengan pembekalan pelaksanaan revitalisasi di Kota Makassar. Kemudian para guru ditingkatkan kompetensi bidang kemaritiman dan TIK dengan kegiatan pembinaan dan dilanjutkan dengan Uji Kompetensi Keahlian (UKK). Selain itu, terdapat pelatihan terhadap laboran kelautan perikanan dan TIK. Suasana diklat PKB program revitalisasi SMK dapat dilihat Gambar 1b.

3. Program keahlian ganda 
Guru yang ditingkatkan kompetensinya program keahlian ganda ini merupakan program sertifikasi pendidik dan sertifikasi keahlian bagi guru SMK/SMA bidang Kemaritiman dan TIK. Ketercapaian output ini pada tahun 2018 yaitu 159,18\%, dengan target 49 orang dapat terealisasi sebanyak 78 orang. Diklat keahlian ganda diawali dengan melakukan diklat instruktur nasional keahlian ganda bidang kemaritiman dan TIK pada bulan Februari sampai Maret 2018. Kemudian diikuti dengan diklat guru peserta diklat bidang keahlian kemaritiman dan TIK pada bulan Maret sampai Juni 2018 bertempat di dua region (Makassar dan Jakarta). Suasana pelatihan program keahlian ganda dapat dilihat pada Gambar 2a-b.

\section{Pelaksanaan Tahun 2019}

Peningkatan kompetensi guru bidang KPTK tahun 2019 diprioritaskan untuk Peningkatan Kompetensi Pembelajaran (PKP) berbasis zonasi, program revitalisasi SMK, guru mata pelajaran informatika, pelatihan guru ke luar negeri, dan keahlian ganda. Total sasaran pada tahun 2019 ini terdiri 9.639 orang dan keahlian ganda 30 orang. Untuk lebih jelasnya, sasaran dan realisasi peningkatan kompetensi guru bidang KPTK tahun 2019 dapat dilihat pada Tabel 5. Berdasarkan Tabel 5, persentase ketercapaian peningkatan kompetensi guru bidang KPTK sangat tinggi yakni mencapai 162,8\%. Hal ini didukung dengan pelatihan guru bidang KPTK yang direncanakan hanya 9.639 orang, tetapi pada pelaksanaannya dengan anggaran yang tersedia, LPPPTK KPTK dapat merealisasikan lebih dari target, realisasi 15.715 orang $(163 \%)$.

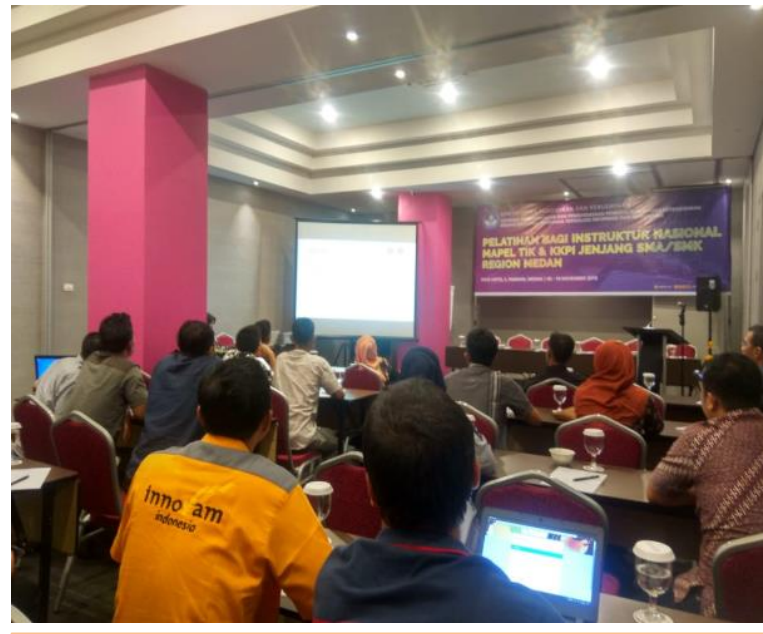

a. Pelaksanaan PKB region Medan

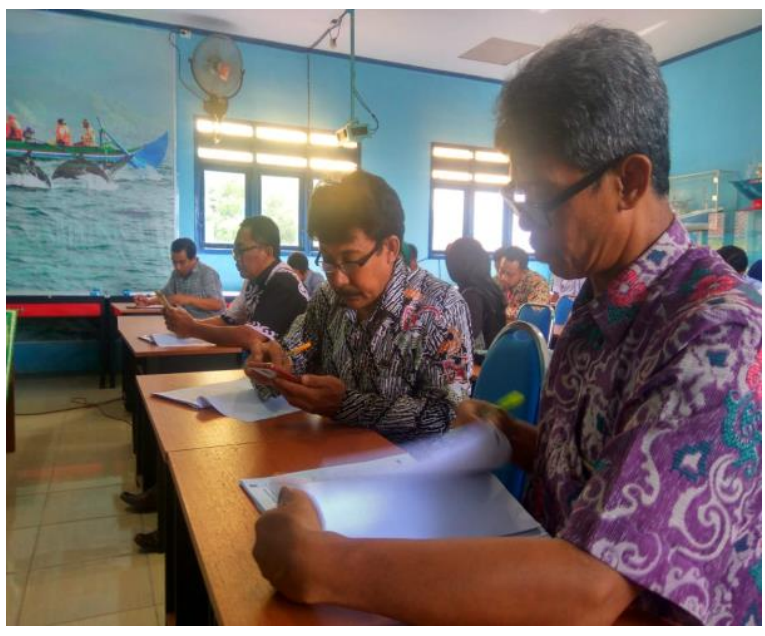

b. Pelatihan guru program revitalisasi SMK

Gambar 1. Suasana pelaksanaan PKB region Medan dan program revitalisasi SMK 


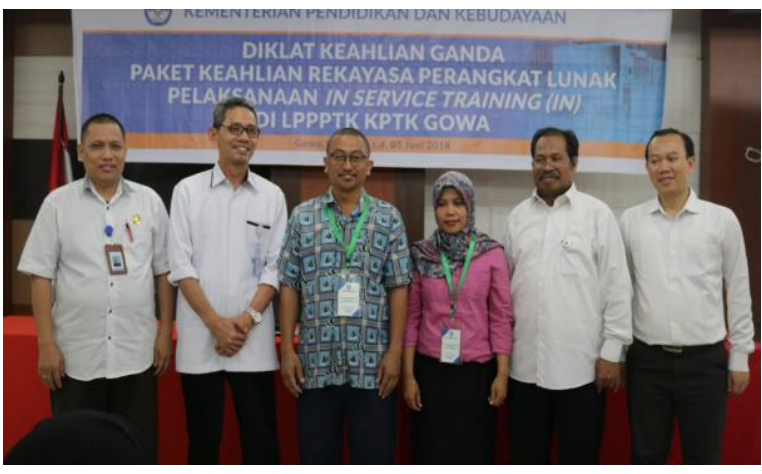

a. Pembukaan Diklat Keahlian Ganda

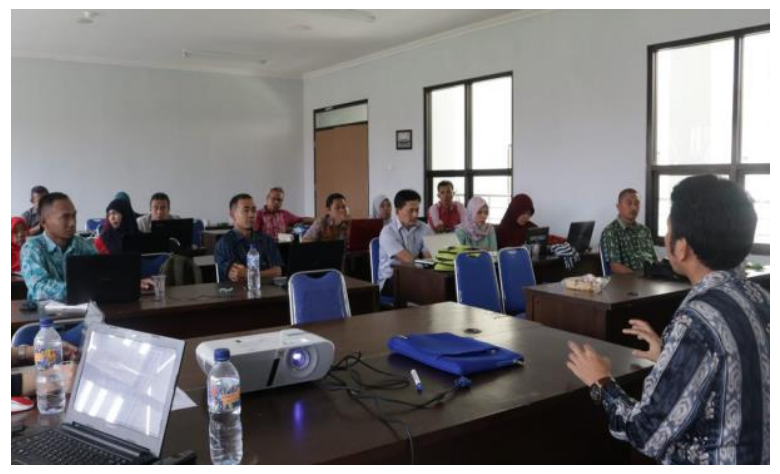

b. Suasana Diklat Keahlian Ganda

Gambar 2. Program keahlian ganda

Tabel 5.

Sasaran dan Realisasi Peningkatan Kompetensi Guru Bidang KPTK Tahun 2019

\begin{tabular}{|l|l|l|l|l|}
\hline No & \multicolumn{1}{|c|}{ Kompetensi Keahlian } & $\begin{array}{c}\text { Sasaran } \\
(\text { Orang }\end{array}$ & $\begin{array}{c}\text { Realisasi } \\
(\text { Orang) }\end{array}$ & $\begin{array}{c}\text { Persentase } \\
\text { Ketercapaian } \\
(\boldsymbol{\%})\end{array}$ \\
\hline 1 & Pelatihan Guru Bidang KPTK & 9.639 & 15.715 & 163,0 \\
\hline 2 & Pelatihan Keahlian Ganda & 30 & 30 & 100,0 \\
\hline & Total & $\mathbf{9 . 6 6 9}$ & $\mathbf{1 5 . 7 4 5}$ & $\mathbf{1 6 2 , 8}$ \\
\hline
\end{tabular}

1. PKP berbasis zonasi bidang KPTK

Pelatihan PKB melalui PKP berbasis zonasi ini merupakan salah satu upaya Kementerian Pendidikan dan Kebudayaan melalui Direktorat Jenderal Guru dan Tenaga Kependidikan (Ditjen GTK) untuk meningkatkan kualitas pembelajaran dan meningkatkan kualitas lulusan dalam hal ini peserta didik. Program ini dikembangkan mengikuti arah kebijakan Kemendikbud yang menekankan pembelajaran berorientasi Keterampilan Berpikir Tingkat Tinggi atau Higher Order Thinking Skills (HOTS). Guru adalah pendidik profesional dengan tugas utama mendidik, mengajar, membimbing, mengarahkan, melatih, menilai, dan mengevaluasi peserta didik. Guru profesional memegang peranan yang sangat penting dalam menentukan prestasi peserta didik. Untuk senantiasa menjaga profesionalitasnya, guru harus senantiasa meng-update dirinya dengan melakukan pengembangan keprofesian berkelanjutan. Kegiatan terbagi dalam beberapa sasaran yaitu; 1. Pelatihan Instruktur Nasional, 2. Pelatihan guru inti tahap 1 sampai 4, ini dilaksanakan pada bulan September hingga bulan November 2019. 
2. Peningkatan kompetensi guru program revitalisasi SMK

Revitalisasi SMK dilakukan dengan bentuk Pelatihan dan Uji Kompetensi Keahlian di bidang Teknika Kapal Penangkap Ikan (TKPI), Uji Kompetensi Keahlian di bidang Nautika Kapal Penangkapan Ikan (NKPI), Uji Kompetensi Keahlian di bidang Multimedia, Uji Kompetensi Keahlian di bidang Teknik Komputer dan Jaringan (TKJ). Terdapat 4 SMK yang dijadikan sebagai pusat belajar (PB) antara lain SMK Perguruan Cikini Jakarta, SMK Wikrama Bogor, SMKS Pelayaran Muhammdiyah Tuban, SMKN 3 Tegal. Kegiatan tersebut diawali dengan pembekalan pelaksanaan revitalisasi di Kota Makassar. Kemudian para guru ditingkatkan kompetensi bidang kemaritiman dan TIK dengan kegiatan pembinaan dan dilanjutkan dengan Uji Kompetensi Keahlian (UKK). Selain itu, terdapat pelatihan terhadap laboran kelautan perikanan dan TIK. Total peserta yang hadir pada kegiatan peningkatan kompetensi guru program revitalisasi SMK ini adalah 100 orang.

3. Peningkatan kompetensi guru mata pelajaran informatika

Peningkatan Kompetensi Guru Mapel Informatika dilakukan dalam bentuk Pelatihan bagi guru Mata Pelajaran Informatika tingkat SMP dan SMA, TOT Mata Pelajaran Komunikasi Digital, FGD Pengembangan Mata Pelajaran Informatika. Untuk pelatihan bagi guru Mata Pelajaran Informatika tingkat SMP dilaksanakan sebanyak 11 Kali di mulai bulan September hingga bulan Desember 2019 di Kota Medan, Kota Makassar, Kota Bandung, Kota Yogyakarta, Kota Surabaya, Kota Malang, serta Kota Palembang yang di ikuti sebanyak 666 Orang guru. Pelatihan bagi guru Mata Pelajaran Informatika tingkat SMA dilaksanakan sebanyak 6 Kali di mulai bulan September hingga bulan November 2019 di Kota Medan, Kota Makassar, Kota Bogor, Kota Yogyakarta, dan Kota Bandung yang di ikuti sebanyak 350 orang guru. TOT Mata Pelajaran Komunikasi Digital dilaksanakan 1 kali di kampus LPPPTK KPTK Gowa pada bulan April hingga Mei 2019 selama 6 hari yang diikuti sebanyak 56 orang.

4. Pelatihan guru ke luar negeri

Dalam rangka menjalankan Program Kementerian Pendidikan dan Kebudayaan Indonesia Tahun 2019 yaitu "Program Pelatihan Guru Ke Luar Negeri", Lembaga Pengembangan Pemberdayaan Pendidik dan Tenaga Kependidikan Bidang Kelautan, Perikanan, Teknologi Informasi dan Komunikasi (LPPPTK KPTK) melakukan Pelatihan 
Guru Bidang Kemaritiman dan TIK Ke Luar Negeri di Korea Selatan selama 7 hari dari tanggal 08 Maret s/d 14 Maret 2019 dan di ikuti 46 peserta yang merupakan para guru di Bidang Kemaritiman dan Teknologi Informasi dan Komunikasi (TIK) dari beberapa daerah di Indonesia.

LPPPTK KPTK memilih Korea Selatan sebagai tempat untuk melaksanakan program pelatihan dengan alasan berdasarkan World Economic Forum on Asia, Hanoi, Vietnam September 2018, Korea Selatan adalah salah satu negara paling berpendidikan untuk tingkat Literasi 100\% di dunia berdasarkan OECD assessment. Disamping itu pada bulan Mei 2017 Presiden Indonesia Joko Widodo menerima kunjungan Presiden Republik Korea di Istana Presiden Bogor, Jawa Barat. Presiden mengatakan Republik Korea adalah mitra strategis dan penting bagi Indonesia karena memainkan peran penting di Kawasan Asean ini. Kerja sama di berbagai sektor antara Indonesia dan Korea sangat intensif.

\section{Keahlian Ganda Bidang KPTK}

Guru yang ditingkatkan kompetensinya program keahlian ganda ini merupakan program sertifikasi pendidik dan sertifikasi keahlian bagi guru SMK/SMA bidang Kemaritiman dan TIK. Ketercapaian output ini pada tahun 2019 yaitu 100\%, dengan target 30 orang dapat terealisasi sebanyak 30 orang. Kegiatan yang mendukung pencapaian indikator tersebut ada 2 (dua) yaitu pelatihan Program Pemenuhan Kompetensi Kerja dan Sertifikasi Keahlian (PKKSK) bagi Calon Pegawai Negeri Sipil Guru Kejuruan Multimedia dan NKPI.

\section{Guru KPTK yang Meningkat Kompetensi Tahun 2015-2019}

Guru KPTK dikatakan meningkat kompetensinya apabila pada akhir pelaksanaan diklat dinyatakan predikat minimal "cukup". Berdasarkan Peraturan Kepala Lembaga Administrasi Negara Nomor 15 Tahun 2015 menyatakan, kategori predikat kelulusan bagi peserta diklat disajikan pada tabel 6.

Jumlah guru yang mendapatkan peningkatan kompetensi pada bidang KPTK dari tahun 2015 sampai 2019 mengalami peningkatan (lihat Gambar 3). Jumlah guru yang mengikuti diklat pada tahun 2018 sebanyak 496 orang. Terdapat kenaikan jumlah yang sangat signifikan pada tahun 2019 yaitu sebanyak 15.745 orang dari target sasaran sebanyak 
9.669 orang dengan persentase ketercapaian sebesar 162,8\%. Dalam hal ketercapaian jika dibandingkan pada tahun 2018 mengalami peningkatan.

Tabel 6.

Kategori predikat kelulusan bagi peserta diklat

\begin{tabular}{|c|c|c|}
\hline No & Skala Nilai & Predikat \\
\hline 1. & $<90,0-100$ & Amat Baik \\
\hline 2. & $<80,0-90,0$ & Baik \\
\hline 3. & $<70,0-80,0$ & Cukup \\
\hline 4. & $<60,0-70,0$ & Sedang \\
\hline 5. & $\leq 60,0$ & Kurang \\
\hline
\end{tabular}

Persentase ketercapaian jumlah guru yang mendapatkan peningkatan kompetensi pada bidang KPTK pada tahun 2018 sebesar 124,3\%. Trend sasaran dan capaian peningkatan kompetensi guru bidang KPTK selama 5 tahun dapat dilihat pada Gambar 3. Berdasarkan Gambar 3, target peningkatan kompetensi guru bidang KPTK LPPPTK KPTK tiap tahunnya bersifat fluktuatif. Hal ini disebabkan adanya perubahan kebijakan dari pusat/pejabat eselon I. Pada tahun 2015 ke 2016 mengalami peningkatan yang sangat signifikan dan mengalami penurunan pada tahun 2016 ke 2017 dan 2018 ke 2019. Kondisi demikian menjelaskan bahwa meskipun target capaian mengalami penurunan pada beberapa tahun, namun dari sisi jumlah realisasi, capaian peningkatan kompetensi guru bidang KPTK mengalami peningkatan. Capaian tersebut juga tidak mempengaruhi target akhir Tahun 2015-2019, dimana sasaran sebanyak 15.096 orang dengan realisasi 20.901 orang atau sebesar $138,5 \%$. Tren persentase ketercapaian peningkatan kompetensi guru bidang KPTK dari tahun 20152019 dapat dilihat pada Gambar 4. 


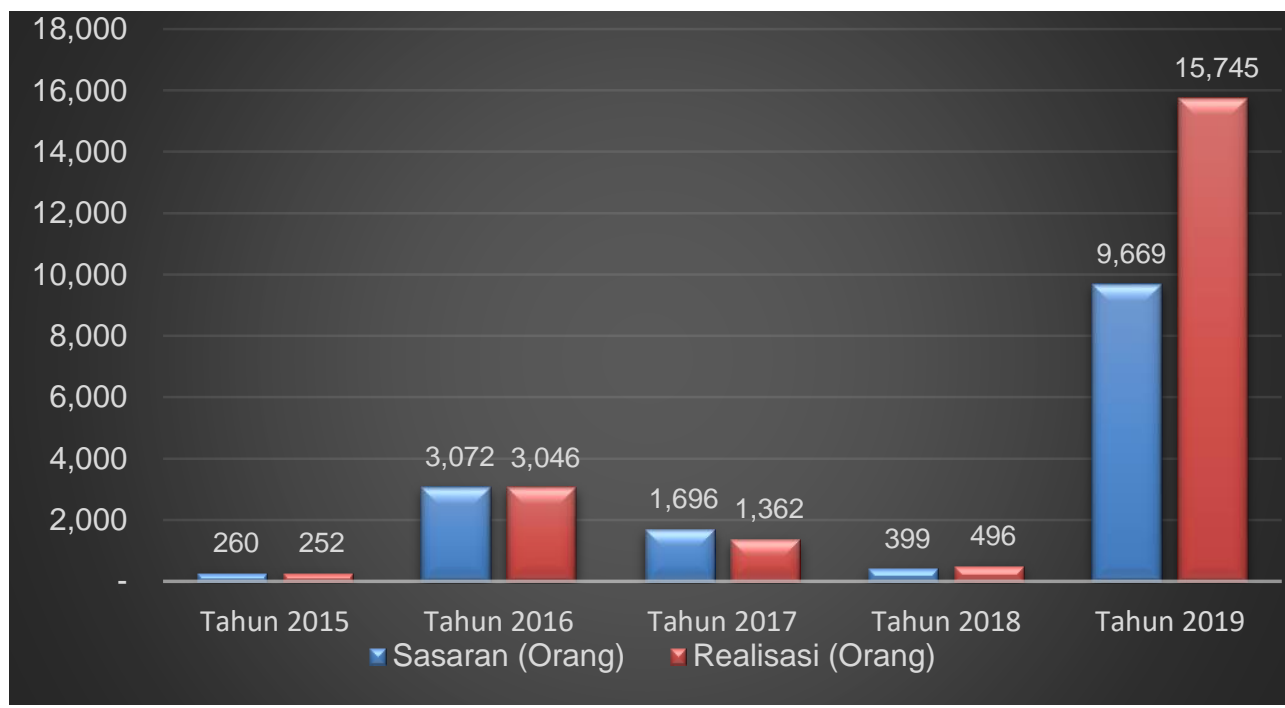

Gambar 3. Trend sasaran dan capaian peningkatan kompetensi guru KPTK selama 5 tahun

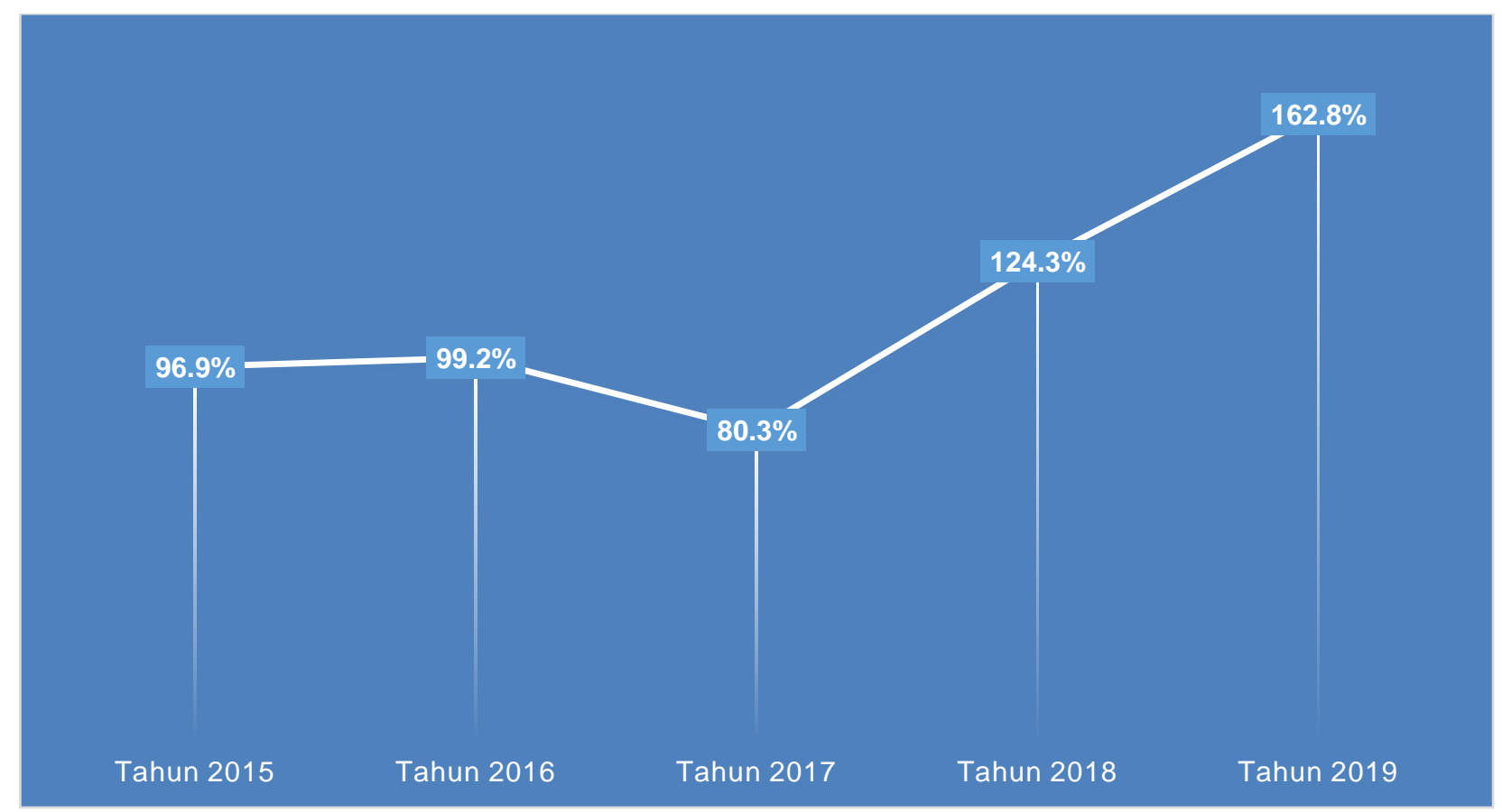

Gambar 4. Persentase ketercapaian peningkatan kompetensi guru bidang KPTK 


\section{PENUTUP}

Peningkatan kompetensi guru bidang KPTK yang dilaksanakan selama lima tahun (2015-2019) dapat disimpulkan sudah efektif. Hal ini terbukti dengan terlaksananya seluruh program diklat sesuai dengan jadwal waktu yang ditentukan, rapinya penyelenggaraan seluruh kegiatan diklat, efisiensi dalam penggunaan sarana dan prasarana yang tersedia, dan tercapainya sasaran yang telah ditetapkan bagi program diklat dari total sasaran 15.096 orang, terealisasi sebanyak 20.901 orang $(138,5 \%)$ atau dapat dikatakan kinerja melampau target yang ditetapkan.

Beberapa hambatan dan permasalahan yang harus diatasi untuk mencapai peningkatan kompetensi guru bidang KPTK adalah penyusunan target peningkatan kompetensi guru bidang KPTK dipengaruhi oleh berbagai kebijakan eksternal diantaranya esselon I dan program prioritas nasional; ketersediaan data yang terbaru sasaran guru KPTK karena data tersebut selalu berubah setiap saat karena guru dan tenaga kependidikan yang bersangkutan telah mutasi, pensiun, ataupun telah meninggal dunia; perubahan pelaksanaan kegiatan sehubungan dengan kesiapan eselon I untuk perangkat diklat yang belum ada; keterlambatan penerbitan petunjuk teknis dan petunjuk pelaksanaan kegiatan peningkatan kompetensi guru KPTK; terjadinya perubahan pagu yang mempengaruhi realisasi baik fisik maupun anggaran; adanya kegiatan yang tidak teralokasikan pada DIPA sebelumnya; adanya tambahan kegiatan menjelang akhir anggaran yang mempengaruhi keterserapan anggaran; perlunya sinkronisasi data yang up-to-date oleh Eselon I dan Dinas Pendidikan terkait sebelum pelaksanaan pelatihan guru KPTK. 


\section{DAFTAR PUSTAKA}

Dewi, L. (2014). Peningkatan Kompetensi Pedagogik Guru Melalui Pelatihan Paikem (Pelatihan Pada Guru Mi Dan Mts Di Kabupaten Cianjur). Edutech, 13 (3), 409. https://doi.org/10.17509/edutech.v13i3.3094

Fitria, H., Kristiawan, M., \& Rahmat, N. (2019). Upaya Meningkatkan Kompetensi Guru Melalui Pelatihan Penelitian Tindakan Kelas. Abdimas Unwahas, 4(1), 14-25. https://doi.org/10.31942/abd.v4i1.2690

Hapsari, M.I., Widiasari, Y. (2018). Efektivitas Pelatihan Komunikasi Positif Terhadap Kemampuan Komunikasi Positif Guru di TK IT Top Kids Sokaraja Purwokerto. Jurnal Ilmiah Kependidikan, XI(2): 144-154.

Julifan, J. (2015). Efektivitas Manajemen Pendidikan Dan Pelatihan Berbasis Kompetensi Bagi Guru. Jurnal Administrasi Pendidikan UPI, 22(2). https://doi.org/10.17509/jap.v22i2.5382

$\underline{\text { Karimah, K. (2016). Evaluasi Keefektifan Diklat Peningkatan Kompetensi atas Kinerja Guru }}$ $\underline{\text { SD dalam Proses Pembelajaran di SD Kota Semarang. Universitas Negeri Semarang }}$

Kurniati, P., Nugroho, B., \& Saragih, F. (2019). Implementation of the Government Credit Card Policy in the Ministry of Foreign Affairs of the Republic of Indonesia. September 2020. https://doi.org/10.4108/eai.30-7-2019.2287577

Nugroho, P. J. (2017). Pengembangan Model Pelatihan Inovatif Untuk Meningkatkan Kompetensi Guru Sekolah Dasar Daerah Terpencil. Sekolah Dasar, 26(2): 101-115.

Putra, S. A., Widyaswari, S. G., Azhar, A., Puspitasari, R. D., \& Parmino, D. V. (2020). Dampak Pelatihan Berbasis Kompetensi Bagi Guru Kejuruan Bidang Kemaritiman di Indonesia. Jurnal Widyaiswara Indonesia, 1(3), 120-129. http://ejournal.iwi.or.id/ojs/index.php/iwi/article/view/18

$\underline{\text { Rusdin. (2017). Pendidikan dan Pelatihan Sebagai Sarana Peningkatan Kompetensi Guru di }}$ SMP Negeri 2 Linggang Bigung. Jurnal Administrative Reform, 5(4), 200-212. 
$\underline{\text { Somantri, O., Abidin, T., Wijayanto, S., Wibowo, D. S., \& Dairoh, D. (2019). Peningkatan }}$ Kompetensi Guru melalui Pelatihan Keterampilan Pembuatan E-Presentation. Jurnal SOLMA, 8(2), 219. https://doi.org/10.29405/solma.v8i2.3245

Sumaryanti, S. (2013). Peningkatan Kompetensi Profesional Guru Melalui Pelatihan ModelModel Pembelajaran Inovatif. Inotek, 17(2): 140-150.

Susilowati, I., Sutanto, H.A., Daharti, R. (2013). Strategi Peningkatan Kompetensi Guru Dengan Pendekatan Analysis Hierarchy Process. JEJAK: Jurnal Ekonomi Dan Kebijakan, 6(1), 80-92. https://doi.org/10.15294/jejak.v6i1.3750

Undang-Undang Nomor 20 Tahun 2003 Tentang Sistem Pendidikan Nasional.

Wardinur, W., \& Mutawally, F. (2019). Peningkatan Kompetensi Guru Melalui Pelatihan Pemanfaatan Teknologi sebagai Media Pendukung Pembelajaran di MAN 1 Pidie. Jurnal Sosiologi USK (Media Pemikiran \& Aplikasi), 13(2), 167-182. https://doi.org/10.24815/jsu.v13i2.16422 